Disponível em

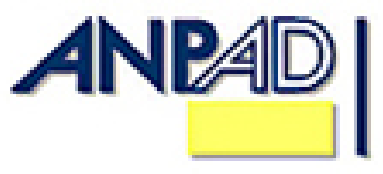

RAC, Rio de Janeiro, v. 19, n. 1, pp. 160-168, Jan./Fev. 2015

http://www.anpad.org.br/rac http://dx.doi.org/10.1590/1982-7849rac20158123 $($ (c) EY-No

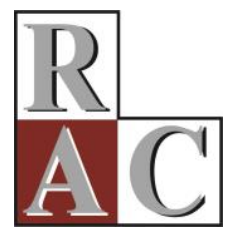

Documentos e Debates:

\title{
Tréplica - Davi e Golias: Possibilidades de Ruptura ao Gigantismo em Estudos Organizacionais e de Gestão
}

David and Goliath: The Possibilities for Overcoming Growth Ideology in Management Studies, a Reply

Rene Eugenio Seifert Universidade Tecnológica Federal do Paraná - UTFPR

Fabio Vizeu Universidade Positivo - UP 


\section{Introdução}

Servindo-nos metaforicamente da história bíblica de Davi e Golias, a perspectiva hegemônica da área de Estudos Organizacionais e de Gestão (EOG) sobre a máxima do crescimento organizacional é encarada, em nosso ensaio, como o gigante a ser superado pelo pequeno guerreiro do pensamento crítico. Sabemos que nosso esforço é encarado por muitos como algo improvável - como parece ser a perspectiva dos revisores de nosso ensaio, mas deixamos este julgamento ao crivo da comunidade acadêmica, que poderá avaliar nosso argumento e de nossos debatedores por meio desta série da sessão Documentos e Debates da Revista de Administração Contemporânea.

Ao considerar o título de nosso ensaio Crescimento Organizacional: Uma Ideologia Gerencial?, facilmente se revela qual é o ponto central de nosso argumento. Assim, refletimos sobre a orientação gerencialista pró-crescimento e posicionamos o argumento de que a busca pelo crescimento organizacional constitui uma ideologia gerencial moderna. Neste sentido, na forma como se apresenta, a orientação gerencialista pró-crescimento configura-se como uma ideologia justamente porque representa interesses particulares, nega contradições e naturaliza o presente. Por conta disso, é importante ressaltar que a ideologia do crescimento organizacional representa um entendimento dominante que, mesmo entre os estudos críticos em Administração (Critical Management Studies), é praticamente inquestionado.

Situamos historicamente as raízes dessa ideologia e, a partir disso, refletimos sobre a necessidade de se estabelecer o diálogo aberto sobre o tema, principalmente, em face da crise socioecológica contemporânea. Ao mesmo tempo, procuramos apontar avenidas de investigação que considerem condutas organizacionais não alinhadas à ideologia do crescimento.

A este argumento recebemos duas réplicas - aqui denominadas por R1 e R2 - ambas feitas a partir de posicionamentos epistemológicos diferentes e, até certo ponto, antagônicos. Ficamos, sinceramente, agradecidos ao editor desta revista por nos proporcionar a possibilidade de refletir sobre tais argumentos, ricos justamente por serem de diferentes naturezas. A partir dessas colocações, pudemos refletir e elaborar nosso próprio contra-argumento, assim, reafirmando nosso tópico central, qual seja, a natureza ideológica do crescimento organizacional.

A seguir, apresentamos de forma sistemática nossa resposta aos comentários e críticas recebidos. Como os dois avaliadores apresentaram perspectivas significativamente diferentes, organizamos nossa tréplica em duas seções, cada uma correspondente a um dos dois revisores. Ainda, encerramos o artigo com uma seção de conclusão.

\section{Tréplica à R1: Crescimento Organizacional, Tamanho das Firmas e Valor Econômico}

A réplica de $\mathrm{R} 1$ ao nosso ensaio reconhece a relevância da temática do crescimento e considera criticamente nossas proposições procurando, ainda, trazer elementos que possam complementar a discussão sobre o tema. A crítica é desenvolvida sob uma perspectiva econômico-financeira fundamentada nos pressupostos da teoria da firma, que aponta a eficiência de mercado enquanto principal mecanismo de regulação do crescimento organizacional.

Apesar de R1 considerar de forma central em sua réplica o crescimento da firma, é importante ressaltar que nossa discussão não procurou limitar-se às lógicas e dinâmicas da firma. De forma mais ampla, consideramos que a ideologia do crescimento informa organizações de forma geral, sejam elas empresas, firmas comerciais ou até mesmo igrejas, clubes, associações e o próprio Estado-nação Moderno. Notadamente, em nossa argumentação, sugerimos que a supervalorização da firma na sociedade moderna é uma manifestação ideológica da sociedade de mercado. 
Sob o ponto de vista dos Estudos Organizacionais Críticos, a hegemonia da lógica de mercado se estabelece pela invasão do enclave social do mercado em outros enclaves nos quais a lógica da racionalidade instrumental se apresenta como contraditória (Ramos, 1989), fazendo com que, por exemplo, tipos organizacionais não econômicos e/ou de forte natureza social transmutem seus princípios fundamentais (Serva, 1997). Ainda, esse entendimento também ecoa o argumento de Milton Santos (2005), ao sugerir que a política de governo dos países ocidentais privilegia os interesses das corporações em detrimento dos interesses da população.

A seguir, consideramos pontualmente as críticas e argumentos desenvolvidos por R1, procurando indicar como tais aspectos se distanciam ou não da perspectiva assumida em nosso ensaio sobre a ideologia do crescimento organizacional.

A primeira preocupação de R1 é que nosso artigo fundamenta-se em uma lente teórica afiliada a um posicionamento analítico que seria tão ideológico quando a ideologia que criticamos. Isto é posto para que R1 justifique um posicionamento de avaliação supostamente isento e cientificamente orientado. Nesta perspectiva, o referido debatedor afirma, por exemplo, que acionistas não devem ser vistos como agentes gananciosos que só pensam em seu próprio bem-estar, mas que o aumento da riqueza do acionista, em última análise, aumenta o bem-estar social.

Ora, há muito tempo se abandonou a premissa positivista da neutralidade científica, já que, desde as sucessivas crises sociais que marcaram o século XX, é sabido que o discurso científico não é neutro e que apresenta um conjunto de interesses que lhe suportam (Habermas, 1987). Desta forma, assumir um posicionamento cientificista de neutralidade só se sustenta dentro dos estreitos limites de uma epistemologia positivista de base funcionalista e legitimada pelo racionalismo instrumental moderno. Nestes termos, a pretensão de neutralidade científica pode facilmente levar a um posicionamento arrogante que ignora suas próprias limitações e alinhamentos ideológicos (B. S. Santos, 1989).

Em razão disso, e sobretudo em nosso ensaio, procuramos especificar bem o conceito de ideologia de que tratamos. Para tanto, recorremos à revisão feita por Giddens (1979) sobre a definição de ideologia em Mannheim, Marx e Habermas. Nestes termos, a argumentação desenvolvida por R1 possui atributos que, de acordo com o referencial conceitual que adotamos, caracterizam o próprio discurso ideológico que denunciamos.

Apesar desse viés, há uma interessante contribuição feita pelo referido debatedor. R1 realiza excelente revisão sobre os conceitos de crescimento organizacional, tamanho da firma e valor econômico, tendo em vista esclarecer suas distinções e sugerir que, no processo crescimento, o tamanho ideal da firma é determinado pelo mercado de capitais, uma vez que este sinalizará se as decisões de crescimento ou decrescimento da empresa são capazes ou não de criar valor. Sinteticamente, para R1, o tamanho ideal da firma é determinado pelo mercado, logo não há razão para regular essa questão. Neste ponto, partilhamos do argumento de Polanyi (2000) ao afirmar que, na sociedade moderna, a noção de mercado é reificada e ideologicamente funcional. Por outro lado, é possível refutar a perspectiva da eficiência de mercado sem entrar no mérito da análise histórica de Polanyi (2000) sobre a constituição ideológica da sociedade de mercado.

O pressuposto de que o mercado é capaz determinar o tamanho ideal das empresas é equivocado pela natureza do comportamento que caracteriza a esfera econômica moderna. Na perspectiva dos defensores do (neo)liberalismo, considera-se o mercado como uma entidade capaz de ordenar a vida social de forma a equalizar e equilibrar crises sociais no longo prazo. Nesse sentido, de acordo com R1, numa economia de mercado: "É importante lembrar que os acionistas só conseguem lucrar se os preços das ações subirem e isso pode não acontecer se o mercado perceber que determinadas decisões podem trazer algum prejuízo social, pelo menos de forma agregada" (p. 146). Ora, é sabido que, na lógica de mercado, não se reconhece a orientação ético-moral como princípio ordenador, mas sim o comportamento oportunístico, baseado no cálculo utilitário de consequências.

Esse traço da era moderna foi identificado por importantes pensadores, tais como Voegelin, Mannheim e os frankfurtianos Horkheimer e Habermas (Ramos, 1989), e não nos cabe revisá-lo aqui. 
É suficiente sublinhar que nosso posicionamento assume que a racionalidade da sociedade de mercado é destituída de orientação ético-moral (Habermas, 1989), logo não sendo possível que os agentes do mercado de capitais julguem moralmente as ações da firma.

Ao considerar a relação entre a idolatria do gigantismo e a crise ecológica, R1 estabelece dois argumentos que merecem consideração. Primeiro, chama atenção para o fato de que a degradação ambiental não deveria ser atribuída exclusivamente à ação das grandes organizações. Concordamos com este entendimento. Notadamente, a degradação ambiental não deve ser atribuída exclusivamente ao gigantismo de algumas organizações. Ainda que os danos e riscos produzidos por organizações de grande porte sejam potencial e proporcionalmente maiores que aqueles de organizações de menor porte, entendemos que a crise ecológica esteja, ainda que parcialmente, vinculada à lógica moderna de progresso e desenvolvimento.

Contudo nosso ensaio sinaliza contundentemente que o valor do desenvolvimento é traduzido na ideologia do crescimento, e que sugere às organizações, grandes e pequenas, que maior é melhor. Nossa intenção ao refletir e denunciar a ideologia do crescimento busca questionar aquilo que Bauman (2001, p. 37) aponta ser a essência do espírito moderno: a incapacidade de ficar parado,

a compulsiva e obsessiva, continua, irrefreável e sempre incompleta modernização; a opressiva e inerradicável, insaciável sede de destruição criativa (ou de criatividade destrutiva, se for o caso: de "limpar o lugar" em nome de um "novo e aperfeiçoado" projeto; de "desmantelar" "cortar" "defasar" "reunir" ou "reduzir" tudo isso em nome da maior capacidade de fazer o mesmo no futuro - em nome da produtividade ou da competitividade).

Segundo, ainda a respeito da relação entre porte e crise ambiental, R1 afirma que a sobrevivência da firma em face da exaustão de recursos naturais amplia a necessidade de grandes investimentos em inovação, pesquisa e desenvolvimento de tecnologias de preservação e conservação ambiental. Logo, na medida em que pequenas empresas se caracterizam por limites de investimento, ganhos de escala e escopo, grandes empresas são necessárias e sempre existirão. Deste modo, R1 sugere que a existência de grandes empresas é imperativo, e conclui que ainda que alguns setores da economia sejam constituídos predominantemente por pequenas empresas, outros setores necessitam de empresas de grande escala.

Entendemos que esse é um argumento de natureza tecnocêntrica. Fundamenta-se na premissa de que a sustentabilidade ou, nas palavras de R1, o desenvolvimento sustentável será possível na medida em que pesados investimentos em tecnologia sejam realizados, o que justificaria a necessidade da existência de empresas de grande porte. Aqui, parece-nos ser importante lembrar o alerta feito por Schumacher (1973) ao discutir a questão das economias de escala. Como observa o autor, existe uma tendência irresistível imposta pela tecnologia moderna para as unidades ficarem cada vez maiores. Nestes termos, a pressão para o crescimento é tanto causa como efeito da tecnologia moderna. Discordamos da visão dominante que sugere que inovação, pesquisa e desenvolvimento tecnológico sejam as únicas saídas para a crise de sustentabilidade contemporânea. Vale lembrar que a crise ambiental agravou-se principalmente num contexto de alto desenvolvimento tecnológico pós-1950.

Em um trabalho prévio (Vizeu, Meneghetti, \& Seifert, 2012), já apresentamos nosso ceticismo na ideia de que mais da causa será, agora, a solução para o problema ecológico. Ao mesmo tempo, não é nossa opinião que a saída para a sustentabilidade seja simplesmente trocar a ideologia do maior é melhor por outra que sugira que menor é melhor. Tal posicionamento seria tão ingênuo e simplista como o que se critica. Nossa intenção ao fomentar o debate a respeito da ideologia do crescimento é chamar atenção para a importância de se promover um diálogo aberto sobre escalas apropriadas às atividades organizacionais; principalmente, apontar avenidas alternativas que vão além da esperançosa crença no desenvolvimento tecnológico. É neste sentido que apontamos para a importância de considerar temas como os limites ao crescimento, as belezas e virtudes do pequeno, a possibilidade da atividade empreendedora ser orientada por significados e propósitos distintos dos resultados financeiros (Fiori \& Seifert, 2013), a gestão regenerativa, a convivialidade (Illich, 1973) e o bem viver (Thompson, 2000; Walsh, 2010). 
Ao considerar essas alternativas, R1 sugere que, apesar de serem relevantes e de caráter nobre, incorporam o risco do desenvolvimento da "criação de um processo paternalista e excessivamente protetor, que incentive a ineficiência e gere um retrocesso no processo evolucionário das firmas e dos modelos de negócio" (p. 146). Entretanto, ao vincular esses temas à necessidade de eficiência, e o possível retrocesso no processo evolucionário das firmas e modelos de negócios, R1 ignora a contraprodutividade da eficiência moderna (Illich, 1973), que, notadamente, é um risco social e ecológico significativamente maior.

Além disso, R1 assume que firmas e modelos de negócio seguem um processo linear e evolucionário de transformação, no qual o melhor substitui o pior. Como afirmamos em nosso ensaio, este é um pressuposto constituinte da ideologia do crescimento, sendo que oferecemos inúmeras evidências das contradições vinculadas a tal argumento. Discordamos que temas como gestão regenerativa e outros que apontamos constituam um retrocesso evolucionário ou que incentivam a ineficiência; pelo contrário, acreditamos que eles incorporam o reconhecimento de que a busca pela eficiência e produtividade deve submeter-se aos interesses e ao bem viver da diversidade dos integrantes que compõem a comunidade da vida.

Finalmente, ao contrário do que afirmamos, R1 sugere que a questão fundamental não é discutir o crescimento em si, mas onde (referindo-se a qual setor) e como crescer. Ou seja, segundo R1, é necessário refletir sobre quais setores da economia poderiam apresentar maiores níveis de crescimento organizacional. A respeito disso, discordamos que a questão fundamental seja refletir sobre setores que devem crescer e como devem fazê-lo. Ainda que tais preocupações encontrem espaço em nosso diálogo, reiteramos nosso posicionamento sobre a importância fundamental de se discutir o crescimento econômico enquanto valor fundamental de orientação da conduta organizacional, na medida em que a discussão e a reflexão sobre os limites e contradições da ideologia do crescimento darão condições para o florescimento de alternativas organizacionais que permitam o bem viver (Latouche, 2009).

\section{Tréplica à R2: Promovendo (De)crescimento em/dos Estudos Organizacionais e de Gestão}

A réplica desenvolvida por $\mathrm{R} 2$ ao nosso texto sobre a ideologia do crescimento organizacional, diferentemente da feita por R1, assume uma posição de crítica ao entendimento dominante, desta forma, alinhando-se ao nosso próprio posicionamento. Neste sentido, verificamos que R2 compartilha de nossa preocupação de que, na área de Estudos Organizacionais e de Gestão (EOG), predomina uma visão ingênua que desconsidera o papel ideológico dos elementos teóricos que sustentam o pensamento acadêmico. Conforme afirma o revisor, é importante considerar que essas concepções ideológicas da área são subprodutos de uma concepção de mundo historicamente constituída que definiu as condições fundamentais de dominação nas sociedades ocidentais e modernas (Vizeu, 2010). Vale notar que essa constatação não é nova, pois outros autores já sinalizaram há algum tempo para o caráter ideológico do Management e dos EORs, tais como Tragtenberg (1974) e Ramos (1989), somente para citar dois importantes autores do pensamento crítico brasileiro.

Todavia R2 constitui como principal elemento de contestação a nossa argumentação sobre o crescimento organizacional o fato de que, supostamente, desconsideramos que esse aparato ideológico presente na área de EOG reflete, antes, uma episteme hegemônica nesta área fundada na relação histórica de colonização. Para sinalizar essa hegemonia, R2 diferencia duas nomenclaturas, uma em português EOG - e outra em inglês - Management and Organization Studies (MOS).

Em razão desse posicionamento, R2 constitui uma enérgica crítica a nossa própria postura, denunciando-a como sendo omissa na busca pela pluralidade, por conta de não expressar uma genuína visão de decoloneidade, esta sim - de acordo com R2 - verdadeiramente plural e menos ideológica.

Entendemos que a argumentação construída por $\mathrm{R} 2 \mathrm{em}$ seus quatro pontos é interessante, mas não concordamos com a linha argumentativa da réplica feita, especialmente se considerarmos o objetivo 
central do nosso texto original. Por conta disso, apresentamos, a seguir, nosso entendimento sobre tal argumento de R2, em que abordamos suas nuanças no decorrer de nossa explanação.

Conforme já salientamos, o texto de R2 constrói uma interessante crítica ao crescimento organizacional a partir da perspectiva decolonial. Assim, a questão da ideologia na área de MOS é considerada acertadamente como sendo uma temática banida pelo mainstream, assim como a política, a despeito da importância destas para a própria compreensão da área enquanto campo social contextualizado; da mesma forma, a questão do crescimento organizacional é retomada por R2 enquanto elemento do projeto civilizatório ocidental colonialista. Mesmo creditando mérito pelo nosso esforço ao sinalizar o crescimento organizacional como uma ideologia, R2 considera ser nossa postura como devedora da mesma ideologia civilizatória euro-americana da qual o conceito que analisamos deriva. Esta suposta contradição do nosso argumento é explorada pela réplica de R2 para demonstrar que, sem se questionar a vinculação de MOS ao projeto civilizatório colonizante euro-americano, não é possível constituir uma alternativa às formas ideológicas dominantes.

Esse parece ser o ponto central do argumento da réplica de R2, que julga nosso esforço insuficiente para tratar da ideologia do crescimento organizacional, já que o referido revisor considera que o nosso texto reproduz o padrão de dominação ideológica dos países metropolitanos sobre as colônias, através da ideia de Ibarra-Colado (2006) de metropolitanidade/colonialidade epistêmica. Sua saída, assim sendo, é pensar no crescimento organizacional da área de MOS sob a égide euroamericana enquanto a verdadeira ideologia a ser questionada.

Ou seja, de acordo com o argumento de R2, a única alternativa viável à ideologia do crescimento organizacional é o enfrentamento de qualquer saída que venha do norte imperialista, porque tais países representam o colonizador opressor que, conforme argumenta R2, manifesta-se no pensamento acadêmico pelo discurso das ciências sociais eurocêntricas. Por conta disso, R2 propõe o crescimento da área de EOG sob uma perspectiva decolonial.

Este argumento de R2 para tratar da problemática do crescimento organizacional indica que a réplica desse revisor foge ao escopo central de nosso ensaio. A essência de nosso argumento original é revelar o conceito do crescimento organizacional tal qual tratado pela área de MOS como fruto do processo histórico de constituição do pensamento moderno, em que a ideologia liberal assume papel central. Nesse sentido, a ideologia de crescimento organizacional certamente é constituinte do projeto civilizatório euro-americano que se opõe à perspectiva decolonial de R2; por isso, acreditamos que não procede a crítica ao nosso texto de que "a análise do âmbito extradiscursivo da ideologia, sob uma perspectiva de decolonialidade é uma lacuna importante na análise efetuada" (p. 153). Mesmo com esta ressalva, o objetivo de nosso ensaio não foi discutir o problema do imperialismo epistêmico (mesmo este sendo considerado em nosso argumento), mas sim o problema da desconsideração da ideia de crescimento organizacional como uma ideologia que não está sendo devidamente tratada na área de EOG. Ao mover o debate para a perspectiva da decolonialidade, R2 foge do ponto central que está em questão.

Por exemplo, a réplica de R2 é omissa na questão do crescimento organizacional enquanto prática vinculada ao processo desenvolvimentista historicamente constituído no escopo da visão eurocêntrica moderna. Ainda, parece-nos que R2, ao pleitear pelo maior espaço da área de EOG advinda das perspectivas do sul, defende que a saída do imperialismo epistêmico é, justamente, o crescimento. Ou seja, além de não tratar da questão central do nosso argumento, R2 reforça a perspectiva que denunciamos, pois assume que as vozes oprimidas devem buscar o mesmo gigantismo que o opressor detém. Metaforicamente, seria igual a dizer que, em relação ao problema da desigualdade social de renda, a solução é fazer com que o pobre se torne rico, enquanto esquece-se que, conceitualmente, para haver o rico é preciso existir o pobre enquanto referência.

Ora, parece-nos que essa postura, além de ingênua, radicaliza qualquer forma objetiva de contraposição à prática do crescimento tal qual apresentada em nosso ensaio. Da mesma forma que não se sustenta mais o marxismo ortodoxo que via de forma maniqueísta a relação de classes dicotomizada 
entre o burguês e o proletário, acreditamos que essa visão radical de decolonialidade também é inviável para buscar saídas objetivas e reais para o problema do crescimento organizacional.

Neste sentido, entendemos que nossa proposta de alternativas para a constituição de modelos de EOG que não sejam baseados exclusivamente na ideologia do crescimento organizacional é pertinente, porque representa uma pluralidade de perspectivas - de ordem ecológica, social, ética e de convivialidade (Illich, 1973). O decrescimento, demonizado por R2 como fruto do projeto civilizatório euro-americano, é apenas uma das alternativas apresentadas; além desta, também mencionamos como alternativas a questão dos limites do planeta, dos problemas sociais solucionados pela organização pequena, a possibilidade de se estabelecer uma racionalidade substantiva em organizações menores (Ramos, 1989; Serva, 1997) e a questão da retomada da convivialidade por novas formas organizacionais.

Nenhuma dessas outras questões foi mencionada por R2, que reduziu nossa argumentação a uma única opção - o decrescimento - que este revisor supôs ser comprometida com uma visão acadêmica colonizante. O revisor considera que o decrescimento é uma estratégia imperialista para evitar o crescimento do outro. Mesmo que isso seja possível, o foco de nossa apreciação do decrescimento é questionar a inevitabilidade do crescimento, que, no argumento de R2, é retomada como um fim desejável e inquestionável. Para evitar a política imperialista na corrida de recursos que deseja usar qualquer forma de limites ao crescimento como estratégia de exclusão do terceiro mundo, assumimos a postura de Milton Santos (2005), a qual indica que o imperialismo das grandes corporações e economias globais se combate com a política que vem de baixo, calcada na soberania do Estado-nação que age em defesa do povo, e não das corporações. Em certo sentido, esta perspectiva é coincidente com a ideia do pequeno (Schumacher, 1973). Essa é nossa ideia de decolonização epistêmica atrelada ao nosso ensaio sobre a ideologia do crescimento organizacional, do modelo corporativo de organizar a vida econômica e social.

Por fim, a pluriversidade de perspectivas anunciada por R2 é contemplada em nosso texto ao considerarmos tantas diferentes avenidas para se pensar em alternativas. Reduzir a questão do crescimento organizacional exclusivamente a uma perspectiva decolonial é que nos parece ser uma atitude imperialista.

\section{Conclusão}

As palavras e opiniões expressas nesse texto não encerram o debate proposto. Pelo contrário, entendemos que sejam o pontapé para a continuidade de um diálogo que julgamos pertinente e relevante. Gostaríamos de manifestar nosso sincero agradecimento à Revista de Administração Contemporânea e seu Editor, por proporcionarem um espaço para que esse diálogo viesse a público e, desta forma, mais vozes pudessem ser incluídas e ouvidas. Neste sentido, também agradecemos as pertinentes considerações dos dois debatedores. Suas réplicas permitiram a interlocução com expressivas perspectivas no campo acadêmico de EOG. Esperamos que os argumentos e opiniões trocados a respeito da ideologia do crescimento estimulem a reflexão e inspirem a busca por alternativas à lógica dominante da gestão moderna.

Nosso envolvimento com o tema nos estimulou à organização do Grupo de Pesquisa em Formas Não Convencionais de Organização, o qual, desde 2013, tem se dedicado a investigar formas de organização, suas causas, princípios, racionalidades, manifestações, impactos, contradições e alternativas a partir de múltiplas perspectivas, epistemologias e campos de conhecimento. Esse esforço justifica-se diante do reconhecimento de que o ideal de prosperidade, progresso e felicidade apregoado pelo modelo de gestão dominante torna-se cada vez mais distante de ser realizado. Tal consideração sugere tanto a incapacidade do modelo hegemônico em solucionar tais problemas como permite que este seja apontado como um dos principais causadores das fundamentais patologias sociais e ecológicas da vida contemporânea (Vizeu et al., 2012). 
Por fim, vale ressaltar que o contexto social brasileiro congrega inúmeras possibilidades de investigação e aprendizagem a respeito dos tópicos que levantamos em nossa crítica à ideologia do crescimento. Principalmente quando se considera os saberes e sabedorias de comunidades tradicionais intrínsecos à formação do povo e da cultura brasileira, tais como os chamados fundos de pastos, sistemas faxinais, quilombolas, bem como as tribos indígenas e as comunidades ribeirinhas de pescadores. Essas experiências organizacionais caracterizadas por tradições e culturas que emergiram à margem do mundo capitalista moderno são ricas, sobretudo, para nos ensinar como pensar em alternativas ao modelo de gestão dominante. Neste sentido, acreditamos que estas formas de organização não convencionais nos possibilitarão melhor compreensão sobre modos de organização orientados por princípios de comunalidade, convivialidade, bem viver, subsistência e solidariedade. Explorar essas experiências, recorrentemente ignoradas pelas abordagens dominantes na pesquisa científica em administração, deverá permitir tanto a compreensão de modos alternativos de organização social e de gestão brasileiros como orientar a construção de modos e práticas de organizacionais mais equilibrados e sensíveis às atuais crises social e ecológica.

\section{Referências}

Bauman, Z. (2001). Modernidade líquida. Rio de Janeiro: Jorge Zahar.

Fiori, D., \& Seifert, R. E. (2013, setembro). Os significados da ideologia do crescimento organizacional: um estudo com empresas de pequeno porte no setor supermercadista. Anais do Encontro Nacional da Associação Nacional de Pós-graduação e Pesquisa em Administração, Rio de Janeiro, RJ, Brasil, 13.

Giddens, A. (1979). Central problems in social theory: action, structure and contradiction in social analysis. Berkeley: University of California Press.

Habermas, J. (1987). Conhecimento e interesse. Rio de Janeiro: Guanabara.

Habermas, J. (1989). Para o uso pragmático, ético e moral da razão prática. Estudos Avançados, 3(7), 4-19. doi: 10.1590/S0103-40141989000300002

Ibarra-Colado, E. (2006). Organization studies and epistemic coloniality in Latin America: thinking otherness from the margins. Organization, 13(4), 463-488. doi: 10.1177/1350508406065851

Illich, I. (1973). Tools for conviviality. New York: Harper \& Row.

Latouche, S. (2009). Farewell to growth. Cambridge: Polity.

Polanyi, K. (2000). A grande transformação: as origens de nossa época. Rio de Janeiro: Campus.

Ramos, A. G. (1989). A nova ciência das organizações: uma reconceituação da riqueza das nações (2a ed.). Rio de Janeiro: FGV.

Santos, B. S. de (1989). Introdução a uma ciência pós-moderna. Rio de Janeiro: Graal.

Santos, M. (2005). Por uma outra globalização: do pensamento único à consciência universal (12a ed.). Rio de Janeiro: Record.

Schumacher, E. F. (1973). Small is beautiful: economics as if people mattered. New York: Harper \& Row.

Serva, M. (1997). A racionalidade substantiva demonstrada na prática administrativa. Revista de Administração de Empresas, 37(2), 18-30. doi: 10.1590/S0034-75901997000200003 
Thompson, J. B. (2000). Ideologia e cultura moderna: teoria social critica na era dos meios de comunicação de massa (5a ed.). Petrópolis: Vozes.

Tragtenberg, M. (1974). Burocracia e ideologia. São Paulo: Ática.

Vizeu, F. (2010). (Re)contando a velha história: reflexões sobre a gênese do management. Revista de Administração Contemporânea, 14(5), 780-797. Recuperado de http://www.scielo.br/pdf/rac/v14n5/v14n5a02.pdf. doi: 10.1590/S1415-65552010000500002

Vizeu, F., Meneghetti, F. K., \& Seifert, R. E. (2012). Por uma crítica ao conceito de desenvolvimento sustentável. Cadernos EBAPE.BR, 10(3), 569-583. Recuperado de http://www.scielo.br/pdf/cebape/v10n3/07.pdf. doi: 10.1590/S1679-39512012000300007.

Walsh, C. (2010). Development as buen vivir: institutional arrangements and (de)colonial entanglements. Development, 53(1), 15-21. doi: 10.1057/dev.2009.93

\section{Dados dos Autores}

Rene Eugenio Seifert

Avenida Sete de Setembro, 3165, Rebouças, 80230-901, Curitiba, PR, Brasil. E-mail: r.e.seifert@gmail.com

Fabio Vizeu

Rua Pedro Viriato Parigot de Souza, 5300, 81280-330, Curitiba, PR, Brasil. E-mail: fabio.vizeu@gmail.com 